\title{
Altababa medical volunteer group mission to Almanagil hospital, Sudan: new ideas for long-term partnership, success factors and guidelines for other groups
}

\author{
G.Y. Ahmed, ${ }^{7}$ I. Hassan, ${ }^{7}$ S. Jafar, ${ }^{7}$ M. Alawad, ${ }^{2}$ A. Jameel, ${ }^{7}$ M. Abdullah' and M. Suror ${ }^{3}$
}

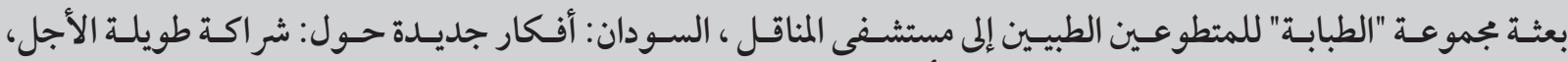

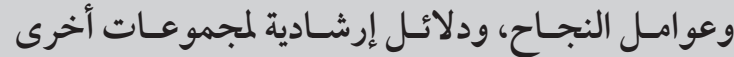

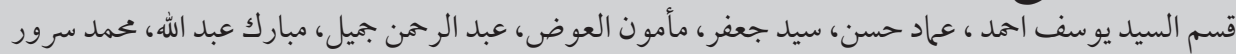

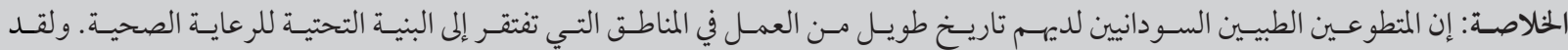

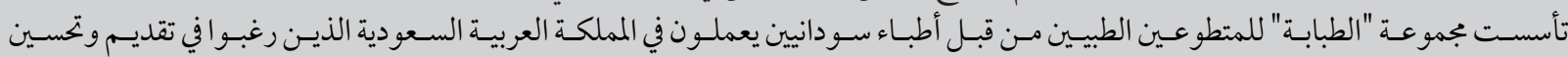

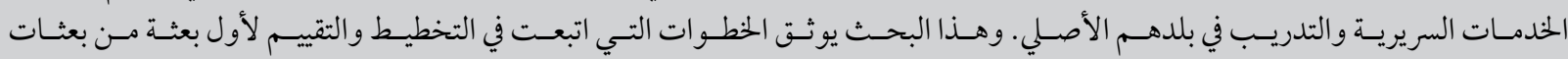

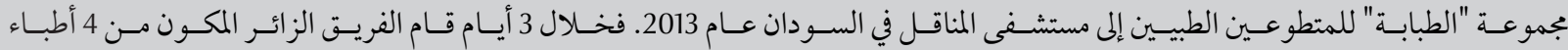

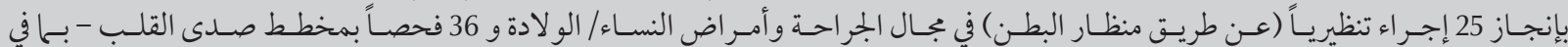

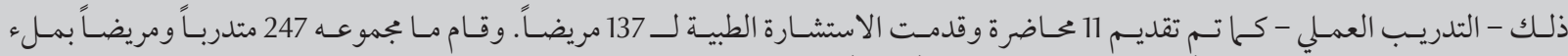

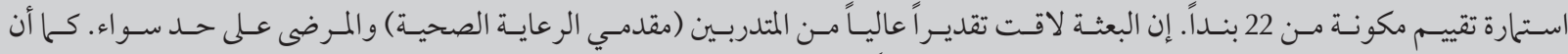

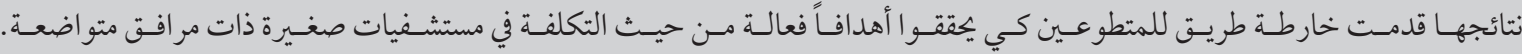

ABSTRACT Sudanese medical volunteers have a long history of working in districts with poor health-care infrastructure. Altababa medical volunteer group (AMVG) was established by Sudanese physicians working in Saudi Arabia who desired to contribute to improving clinical services and training in their country of origin. This paper documents steps in the planning and evaluation of AMVG's first mission to Almanagil hospital in Sudan in 2013. Over a 3-day period the visiting team of 4 physicians performed 25 laparoscopic surgical and obstetric/ gynaecological procedures and 36 echocardiogram tests-all with hands-on training-presented 11 lectures and consulted with 137 patients. A total of 247 trainees and patients completed a 22-item evaluation survey. The first mission was highly rated by both trainees (health-care providers) and patients. The results provided a road map for volunteers to accomplish cost-effective goals in small hospitals with modest facilities.

Mission du groupe de bénévoles médicaux Altababa à l'hôpital Almanagil au Soudan : idées nouvelles pour un partenariat à long terme, facteurs de succès et lignes directrices pour les autres groupes

RÉSUMÉ Les bénévoles médicaux soudanais ont une longue expérience en matière d'activités dans les districts où les infrastructures de soins de santé sont médiocres. Le groupe de bénévoles médicaux Altababa a été créé par des médecins soudanais en exercice en Arabie saoudite souhaitant contribuer à l'amélioration des services cliniques et à la formation dans leur pays d'origine. Le présent article détaille les étapes de planification et d'évaluation de la première mission du groupe de bénévoles médicaux à l'hôpital Almanagil au Soudan en 2013. Sur une période de trois jours, l'équipe en visite de quatre médecins a réalisé 25 interventions laparoscopiques, obstétricales/ gynécologiques, et 36 examens échocardiographiques, systématiquement accompagnés de formation pratique. Ils ont aussi donné 11 conférences et reçu en consultation 137 patients. Au total, 247 stagiaires et patients ont répondu à une enquête d'évaluation en 22 items. Cette première mission a reçu un score élevé de la part des stagiaires (professionnels de santé) et des patients. Les résultats fournissent une feuille de route aux bénévoles pour atteindre des objectifs d'un bon rapport coût-efficacité dans de petits hôpitaux dotés d'installations modestes.

'King Abdulaziz Medical City, Riyadh, Saudi Arabia (Correspondence to G.Y. Ahmed: gasmelseedahmed@gmail.com). ${ }^{2}$ King Fahad Medical City, Riyadh, Saudi Arabia. ${ }^{3}$ Almanagil Teaching Hospital, Almanagil, Sudan.

Received: 15/02/15; accepted: 12/05/15 


\section{Introduction}

Medical missions are a means of extending the reach of health-care professionals to the underdeveloped world and a number of organizations and countries provide medical care through such initiatives. The term medical mission reflects its origins as a part of religious missionary work. Health-care professionals from the developed world frequently volunteer to serve on medical mission trips to countries with large, medically underserved populations, with the wider aim of improving the health of people worldwide and reducing health disparities among populations. Although some of these professionals may be paid staff members of various agencies, many are volunteers who work with small nonprofit/nongovernmental organizations (NGOs). Members of volunteer groups commonly include physicians, nurses, pharmacists, other health professionals and students. In 2005, there were as many as 5000 health volunteers working in sub-Saharan Africa alone, 1500 of whom were physicians (1). Volunteer groups frequently comprise members of religious or civic groups who have an interest in health in the developing world. They raise funds, recruit volunteers, purchase medical supplies and provide medical and/or public health services. In most cases, volunteer groups return to the same area annually to provide short-term services. Estimates of the efforts expended by volunteer groups suggest that the United States alone has over 500 mission organizations that send up to 6000 mission trips per year (1).

The missions can have a significant impact not only on patients but also on the health-care workers themselves. Personal reflections of volunteers suggest that those who serve on medical missions view their experience positively and find it personally rewarding (1-3). Although volunteers hope such work will assist underserved populations, medical mission groups have been criticized for not providing sustainable health services that focus on underlying health problems (3). Lack of follow-up data, poor relations with the local health-care system and lack of sustainability can challenge the goals and intentions of these missions. Despite a total of over US\$ 250 million and thousands of volunteer-hours dedicated to short-term medical missions, there is lack of standardized evaluation to assess patient safety, quality control and mission impact $(4,5)$ and there is a paucity of literature on the impacts of international medical volunteering and ways to optimize the benefits of such placements. Various authors have raised concerns that short-term medical volunteer missions have the potential to be harmful to recipient communities; however, the social science and medical literature contains little research into the perceptions of short-term medical volunteer work (6-8). Country experts, for example, have expressed more negative than positive views about international health volunteers and see them as increasingly paradoxical in view of the existence of urban unemployed doctors and nurses in most countries (9).

Altababa medical volunteer group (AMVG) is a Sudanese nonprofit medical volunteer group established in December 2013 with the primary goal to initiate and maintain a charitable strategic long-term partnership between Sudan and expatriate Sudanese medical professionals in Saudi Arabia. This article is a report of AVMG's first experience in sending a voluntary medical mission to Almanagil hospital. We aimed to shed some light on our efforts and to produce strategic guidelines for the success of similar trips and workshops in the future. Some of our study results may help address questions about the perceptions of doctors and patients in Sudan on these voluntary missions and about local doctors' acceptance of their emigrant colleagues. It may also help remove concerns that many missions may have about the failure to conduct successful workshops in small cities with scarce facilities and limited resources.

\section{Methods}

\section{AMVG establishment}

AMVG is a nonprofit organization established in 2013 by Sudanese physicians working for the Saudi National Guard, Riyadh, Saudi Arabia. The primary incentive for its formation was the members' desire to make a positive contribution to benefit the health-care services and fellow citizens in their country of origin. The membership soon expanded to include doctors from other hospitals in Saudi Arabia, with a plan to recruit more members from among the health-care providers in the Sudanese diaspora. Unlike other voluntary groups, AMVG emphasized that it would seek to establish long-term strategic partnerships, primarily with small- to medium-sized hospitals and health-care establishments, a maximum of 2 at any one time and principally located in peripheral and rural areas. The aim of such a partnership was to focus on underprivileged institutions and to build a long-term collaboration with these bodies to assist them in becoming model centres, before moving into other similar facilities. The group also used online social media by establishing WhatsApp and Google group web-pages to facilitate communication as well as upload the group's resources and products. The 3-day trip reported here was the first mission carried out by AMVG.

\section{Site selection}

Almanagil was nominated as the first mission site by 2 members of AMVG who are originally from the city. They submitted a supportive proposal about the demographic health map of the area, the epidemiological characteristics of the population and the needs of the hospital. AMVG reviewed the proposal as well as proposals for other suggested 
areas. Almanagil hospital was eventually approved.

Alamangil city is located in the west of the central region of Sudan. It is the extension of Aljazeera agricultural scheme with a population of 1200000 , most of them farmers. It is a large area covering: Alhuda town and rural areas, Alazazi town and rural areas, Alkiraimit town and rural areas, Almaatoori, Algamoosi, Algurashi town and Maatooq (10).

\section{Setting up the mission}

\section{Programme design}

AMVG designed their programme and a partnership agreement to be signed by Almanagil hospital administration prior to the visit. The partnership agreement covered the role of AMVG in providing trainers and the role of the hosting hospital in providing all the required logistic facilities, including accommodation, classrooms, offices, prepared operating room and anaesthesiologist, and opening and closing ceremonies. The chief executive of Almanagil hospital designated a staff member as a coordinator for communication and logistic preparation of the workshops. AMVG sent a skills' inventory of different specialists for the coordinator to select the programmes that suited the hospital's needs. Communication between the parties ended in a consensus of 4 specialties; evidence-based medicine, surgery, cardiology and obstetrics/ gynaecology workshops. Candidate patients were recruited and notified by the hospital's specialists. Advertisements were made and interested health-care provider trainees were registered by the coordinator.

\section{Logistic preparations}

Frequent team meetings and orientation for all AMVG participants was done before the trip and a group covering 4 areas of expertise with excellent training skills were nominated to run the mission, supported by a research epidemiologist to conduct a concomitant survey. The programme contents, the mission schedule and information on the duties were emailed to the $\mathrm{Al}$ managil hospital team. The travelling members sponsored all costs of their flights and accommodation. Drugs and equipment were prepared by Almanagil hospitals in accordance with the partnership agreement. As stated in the mission of AMVG, a request was made for Almanagil senior doctors and section heads to participate in the workshops and to prepare the local programmes.

\section{Training and health-care services}

The team provided health-care services and training programmes during the visit. Patients received full diagnosis with management and junior physicians received hands-on training in laparoscopic surgery, obstetric/gynaecological laparoscopic procedures and echocardiography.

\section{Evaluation of the mission}

\section{Ethical approval and sampling}

The proposal for this evaluation study was approved by the institutional review board of the University of Gezira, Sudan. All health-care providers who attended the training and all patients who consulted or underwent laparoscopic procedures in the workshops were recruited consecutively and interviewed for their feedback on the mission, after their verbal consent for participation was obtained.

The mission was evaluated by assessing the satisfaction level of beneficiary candidates (health-care provider trainees and patients). A data collection form was designed consisting of 22 items concerning sociodemographic variables, opinions about the content of the AMVG activities and suggestions for modifications and improvements to future workshops. Responses were scored on a Likert-type scale from 1 to 5 , with 1 being least satisfied and 5 denoting strongly satisfied. The data collection form was designed in both Arabic and English languages and its construct characteristics were consensually validated before use.

The data collection form was distributed to all attendees at the beginning of the workshops and to all patients after consultation or recovery from procedures.

Descriptive analysis was conducted using SAS statistical software, version 9.2 .

\section{AMVG team feedback report}

At the end of the workshops the team returned back to their workplaces and held a meeting for the assessment of the mission. A comprehensive feedback report indicating all key interventions targeting improvements was acknowledged by AMVG members and a copy was mailed to Almanagil hospital staff as the first practical step for a future sustainable partnership.

\section{Results}

Over a 3-day period the visiting team trained 110 health-care professionals and consulted with 137 patients, performed 25 laparoscopic surgical and obstetric/gynaecological procedures and 36 echocardiagrams - all with hands-on training - and presented 11 lectures. Most of the procedures were laparoscopic cholecystectomies, while other operations ranged from minor inguinal hernia repairs to major procedures such as Nissen fundoplication and some diagnostic gynaecological laparoscopies.

A total of 137 patients (55.5\%) and 110 trainees $(54.5 \%)$ returned filled evaluation questionnaires, a response rate of $91.3 \%$ and $95.7 \%$ respectively. Among the health-care practitioners 78 (31.6\%) were physicians (18 consultants, 24 registrars, 31 medical officers and 5 house officers), 21 (8.5\%) were medical students and 11 (4.5\%) were nurses (Table 1). Females were $53.4 \%$ of respondents. Most respondents (77.7\%) indicated that this was their 


\begin{tabular}{|c|c|c|c|c|}
\hline \multirow[t]{2}{*}{ Attendees' characteristics } & \multicolumn{2}{|c|}{ Health-care professionals trained } & \multicolumn{2}{|c|}{ Patients diagnosed and treated } \\
\hline & No. & $\%$ & No. & $\%$ \\
\hline Total & 110 & 100.0 & 137 & 100.0 \\
\hline \multicolumn{5}{|l|}{ Sex } \\
\hline Male & 51 & 46.4 & 64 & 46.7 \\
\hline Female & 59 & 53.6 & 73 & 53.3 \\
\hline \multicolumn{5}{|c|}{ Attended a similar mission before } \\
\hline Yes & 24 & 21.8 & 31 & 22.6 \\
\hline No & 86 & 78.2 & 106 & 77.4 \\
\hline \multicolumn{5}{|l|}{ Job description } \\
\hline Consultant & 18 & 16.4 & - & - \\
\hline Registrar & 24 & 21.8 & - & - \\
\hline Medical officer & 31 & 28.2 & - & - \\
\hline House officer & 5 & 4.5 & - & - \\
\hline Medical student & 21 & 19.1 & - & - \\
\hline Nurse & 11 & 10.0 & - & - \\
\hline
\end{tabular}

first time to attend voluntary mission workshops. Patients seen came primarily from the Almanagil and the surrounding villages, while trainees came from 11 different cities from all over the country. The mean age of the attendees was 30.9 (SD 9.9) years.

In their evaluation of the mission between $71.3 \%$ and $92.3 \%$ of participants strongly agreed about the richness of the programme in terms of: convenience of venues and time, good communication and a positive contribution of expatriate faculty to improvement in health-care provision. Asked about overall satisfaction with the programme, $91.9 \%$ strongly agreed and $8.1 \%$ somewhat agreed. A total of $91.5 \%$ strongly recommended that such activities should be regularly undertaken. A high percentage (78.5\%) strongly agreed that NGOs and government bodies should arrange such missions (Table 2).

Respondents indicated that the most useful component of the mission was diagnosis and management, i.e. the patient-directed activities (32.5\%), followed by training about professional communication, i.e. the doctor-patient relationship (23.2\%), while the theoretical and video presentations were valued only by $4.5 \%$ of participants. The least helpful part of the workshops according to the participants was related to timing, i.e. activities being conducted on weekdays (8.9\%), and the short allocated time for sessions and the workshops as a whole (3.7\%) (Table 3).

\section{Discussion}

This was the first study in Sudan to document the steps in formation of a voluntary group and an evaluation of the programme in its first round of medical volunteer work. AMVG members' strategic approach focused on specific collaborative projects to assist an institution in becoming a model centre providing support and services to multiple institutes, and this is a clear departure from the norm of such missions. In contrast with some other missions regionally and globally, we conducted advanced laparoscopic procedures ranging from inguinal hernias, cholecystectomy to Nissen fundoplication. In other missions, health-care professionals typically provide only for basic health needs, ranging from primary care to surgical relief (11). Through this kind of approach, overseas volunteers can benefit by broadening their expertise by treating patients with conditions virtually unseen in their countries and while volunteering in the local facilities provide practical skills' building (12). In our mission the most favoured activities were the hands-on skills acquired by trainees, a process quickly endorsed by Almanagil's partners.

The familiarity of our team with the area and the lack of language barriers assisted in the success of the mission. In similar situations, volunteers wrestle with a core set of challenges that distinguish overseas medical work from their usual clinical routine, in addition to a preoccupation with avoiding complications that may arise from working with unfamiliar colleagues in a foreign setting and caring for patients who speak a different language. These barriers mean that most volunteer surgeons avoid cases that carry a high risk of complications or protracted recovery. In most missions, complications that do occur are often attributable to insufficient screening of patients or inadequate follow-up, and therefore large organizations send an advance screening team and leave a group behind to provide follow-up care (13). 


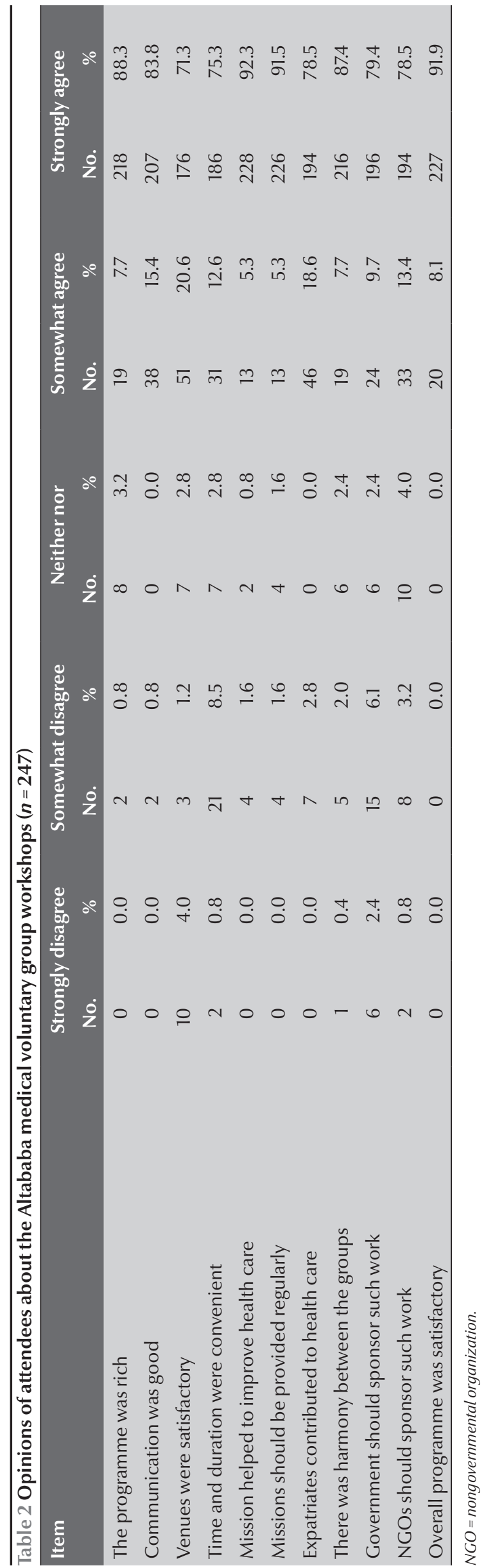

Our first mission was clearly a success based on feedback from the participants and beneficiaries. Health-care workers expressed a high-level of satisfaction with the mission's endeavours. There was a clear general agreement that expatriate medical practitioners have an important and welcomed role in providing and improving health-care to their fellow citizens in underprivileged areas. Additionally, there was a high level of agreement that such input is valued and should be continued. Many respondents would welcome having other specialties or disciplines covered by the programme. They also agreed that more time could be allocated for various activities and more visits planned and that these should be advertised in advance to cover other health centres.

Several factors clearly contributed to the smooth running and success of our mission. The most important reason was the presence of 2 physicians in AMVG who were originally from the area and who sponsored contacts between the volunteer team and the hospital site. This facilitated the building of trust and harmony between the group and the Almanagil hospital team as well as communication and programme finalization between the 2 partners. Forwarding a skills inventory to Almanagil's team allowed them to select what they needed most, making the final programme appealing to the administration. Another factor in the success of this mission was the keenness and enthusiasm of not only the AMVG but also the Almanagil hospital's administrative team. The latter embarked on preparing for this event by forming an action group to prepare for the visiting colleagues and their programme. The support provided to Almanagil's team by government bodies headed by the State Minister of Health and his team as well as the benevolence of Almanagil's people left no room for failure. Added to that, well-organized planning and logistic support from nonofficials and officials were identified as success factors. A study of volunteer cleft missions worldwide noted that: "It was impossible for the taskforce to achieve a successful mission without goal organization and close coordination." (14). Throughout their mission AMVG did their job in harmony within their group and with the hosting team. A study of pharmacy students participating in domestic and international medical missions noted that "usually team unity, the level of respect for members, and their ability to lead trips serve as effective role models of servant leaders" (2).

This volunteer trip provided excellent experience for conducting research concomitantly with workshops. In addition to providing medical aid and training, the mission is believed to have promoted professional relationships and social networking between the involved physicians. This may eventually assist in facilitating future collaboration and success. Regardless of physicians' personal opinions about the political situation in Sudan, our mission encouraged a positive push in the direction of building capacity and infrastructure.

The study, based on the mission and vision of AMCG together with the enthusiasm of the hosting hospital staff and their interest in conducting similar workshops annually, has 


\begin{tabular}{|c|c|c|}
\hline Item & No. & $\%$ \\
\hline \multicolumn{3}{|l|}{ Which part of the services was most useful and helpful to you? $(n=110)$} \\
\hline Diagnosis and management & 80 & 72.7 \\
\hline Communication training & 57 & 51.8 \\
\hline Cardiology, ECG, ECHO training & 55 & 50.0 \\
\hline Laparoscopy training & 27 & 24.5 \\
\hline All parts & 17 & 15.5 \\
\hline Theoretical and video presentations & 11 & 10.0 \\
\hline \multicolumn{3}{|l|}{ Which part of the services was least useful and helpful to you? $(n=247)$} \\
\hline None & 216 & 87.4 \\
\hline Being on weekdays & 22 & 9.8 \\
\hline The time was short & 9 & 4.0 \\
\hline \multicolumn{3}{|l|}{ Would you recommend a similar activity for other hospitals? $(n=247)$} \\
\hline Yes & 243 & 98.4 \\
\hline No & 4 & 1.8 \\
\hline \multicolumn{3}{|l|}{ Would you attend and advise a colleague/friend to attend in the future? $(n=247)$} \\
\hline Yes & 237 & 96.0 \\
\hline No & 10 & 4.0 \\
\hline \multicolumn{3}{|l|}{ What should be added next time to improve such visits? $(n=110)$} \\
\hline Add endoscopy & 50 & 20.2 \\
\hline Add orthopaedics & 24 & 9.7 \\
\hline Add ophthalmology & 17 & 6.9 \\
\hline Add paediatric cardiology & 16 & 6.5 \\
\hline Add emergency room care, advanced life support, basic life support & 10 & 4.0 \\
\hline Add radiology training & 8 & 3.2 \\
\hline Other suggestions & 11 & 4.5 \\
\hline \multicolumn{3}{|l|}{ Do you have any other suggestions for future improvement? $(n=247)$} \\
\hline Early arrangements with patients and use of media advertisements & 104 & 42.1 \\
\hline Do it twice per year & 72 & 29.1 \\
\hline Medicine and equipment supplies & 61 & 24.7 \\
\hline Each volunteer group sponsor a hospital & 31 & 12.6 \\
\hline Improve venues (air-conditioning) & 21 & 8.5 \\
\hline Programme for medical students, nurses and operating room assistants & 20 & 8.1 \\
\hline Best times are winter, weekends, nights & 18 & 7.3 \\
\hline Cover other hospitals & 10 & 4.0 \\
\hline Other suggestions & 21 & 8.5 \\
\hline
\end{tabular}

$E C G=$ electrocardiography; $E C H O=$ echocardiography.

great expectations for future sustainable long-term partnership with the targeted hospitals that could last beyond the duration of the trip and be achieved through communication and planning for new missions. Through partnership, our collaboration was innovative and overcame bigger challenges despite the limited resources.
Communities in remote rural hospitals are in real need of services. However, conducting missions to these areas entails considerable difficulties. Hoover et al. reviewed experiences of a private volunteer medical organization in sub-Saharan Africa and noted that "The lack of standardization, vintage laboratory equipment, a manual medical record system, lack of subsidized transportation system, infrequent postal service and the absence of phone system in the remote provinces and villages make treatment and tracking of patients, monitoring therapy and measuring outcomes/ results difficult." (15). In this trip, our team faced minor logistic difficulties 
especially at the level of operating rooms, which have been included in the team's report to Almanagil hospital administration for future improvements. However, these had no significant impact on the mission's outcome.

In general, the benefit of our mission was limited by several factors: the workshops were performed during the time when some hospital practitioners were busy with their private practice, which clearly hindered their full participation. A lack of some medical equipment was another limiting factor. The last-minute failure of our evidence-based medicine specialist to obtain an entry visa created a gap in our programme which necessitated the other specialists to fill it by presenting brief talks about evidence-based medicine during their scheduled presentations. Finally, concerns about ethical problems and the lack of pre-surgical assessment and post-surgical follow-up for patients who had certain interventions need to be appraised.

\section{Conclusions}

In this study we identified the main factors behind the smooth running and success of our mission. Some were inherent to the volunteer group, its members and its vision of long-term goals, while others were related to the targeted institute, its administration and the support from government and local nongovernmental bodies. This report has explored the obstacles facing volunteer medical work and at the same time established guidelines to combat these difficulties which could be applied by other volunteer groups to achieve their goals efficiently.

\section{Recommendations}

- The team should outline recommendations for future missions based on clear objectives, organization, personal health and liability, funding, trainee and public relations.

- Volunteer groups can sponsor certain hospitals in each region of the country and establish twinning and partnership with them for capacitybuilding of the local staff and hospital facilities. These sponsored institutes may then act as future independent training satellite centres for other hospitals.

- Conducting frequent workshops and continuous online communication may help strengthen and augment such successes.

- Early preparations of candidate patients and early communication with them are necessary for satisfactory clinical outcomes.

- Small groups of active coordinators ought to be recruited in Sudan, to act as support teams for future programmes and visits.

- Volunteer teams should write a feedback report after each visit and the beneficial hospital staff in Sudan should take responsibility to incorpo- rate and implement its recommendations for future improvement of the local health-care system.

- Arrangements between emigrant health-care providers and the State authorities is needed to draft a proper strategy for collaborative work.

- A database of all health-care providers in the Sudanese diasporas can be set up to identify candidates for future engagement as health manpower and to facilitate identifying priorities and monitoring progress of service delivery through regular surveys.

\section{Acknowledgements}

The authors wish to gratefully acknowledge the team members who provided the services in this trip and in paying for their flight tickets. Authors would also want to extend their thanks for the assistance offered by all stakeholders who facilitated accommodation and transportation. We formally like to acknowledge the efforts of Dr Alfatih Izeldeen, Chair of the National Assembly, the businessmen of Almanagil city, AbuDryra, Jamoha and DafaAllah, the College of Animal Production and Almanagil hospital staff.

Funding: The travelling members of AMVG sponsored all costs of their flight tickets and other expenses related to transport from their hospitals to the airport.

Competing interests: None declared.

\section{References}

1. Rovers J, Andreski M, Gitua J, Bagayoko A, DeVore J. Expanding the scope of medical mission volunteer groups to include a research component. Global Health. 2014;10:7. PMID:24555713

2. 2. Brown DA, Fairclough JL, Ferrill MJ. Planning a pharmacy-led medical mission trip, part 4: an exploratory study of student experiences. Ann Pharmacother. 2012 Sep;46(9):1250-5. PMID:22892269

3. Snyder J, Dharamsi S, Crooks VA. Fly-By medical care: Conceptualizing the global and local social responsibilities of medical tourists and physician voluntourists. Global Health. 2011;7:6. PMID:21470415

4. Maki J, Qualls M, White B, Kleefield S, Crone R. Health Impact assessment and short-term medical missions: a method study to evaluate quality of care. BMC Health Serv Res. 2008;8:121.

5. Mulvaney SW, McBeth J. Medical humanitarian missions. Am Fam Physician. 2009 Mar 1;79(5):359-60. PMID:19275063

6. Suchdev P, Ahrens K, Click E, Macklin L, Evangelista D, Graham E. A model for sustainable short-term international 
medical trips. Ambul Pediatr. 2007 Jul-Aug;7(4):317-20 PMID:17660105

7. Elnawawy O, Lee AC, Pohl G. Making short-term international medical volunteer placements work: a qualitative study. $\mathrm{Br} J$ Gen Pract. 2014 Jun;64(623):e329-35. PMID:24868070

8. Green T, Green H, Scandlyn J, Kestler A. Perceptions of shortterm medical volunteer work: a qualitative study in Guatemala. Global Health. 2009 Feb 26;5:4. PMID:19245698

9. Laleman G, Kegels G, Marchal B, Van der Roost D, Bogaert I, Van Damme W. The contribution of international health volunteers to the health workforce in sub-Saharan Africa. Hum Resour Health. 2007;5:19. PMID:17672889

10. Sudan Central Bureau of Statistics [Internet] (http://www.cbs gov.sd/files.php?id=7\#\&panel1-1 accessed 2 June 2015) [in Arabic].
11. Martiniuk AL, Manouchehrian M, Negin JA, Zwi AB. Brain Gains: a literature review of medical missions to low and middle term-income countries. BMC Health Serv Res. 2012;12:134. PMID:22643123

12. Vastag B. Volunteers see the world and help its people. JAMA. 2002 Aug 7;288(5):559-65. PMID:12150654

13. Wolfberg AJ. Volunteering overseas-lessons from surgical brigades. N Engl J Med. 2006 Feb 2;354(5):443-5. PMID:16452555

14. Yeow VK, Lee ST, Lambrecht TJ, Barnett J, Gorney M, Hardjowasito W, et al. International Task Force on Volunteer Cleft Missions. J Craniofac Surg. 2002 Jan;13(1):18-25. PMID:11886986

15. Hoover EL, Cole-Hoover G, Berry PK, Hoover ET, Harris B, Rageh D, et al. Private volunteer medical organizations: how effective are they? J Natl Med Assoc. 2005 Feb;97(2):270-5. PMID:15712791 